\title{
A SENSORLESS PM SYNCHRONOUS MOTOR DRIVE FOR ELECTRIC WASHERS
}

This paper presents a complex solution for whole speed range sensorless control of interior permanent magnet synchronous motor drives. To cover an entire speed range of IPMSM without position transducer, different sensorless techniques must be employed. Design and implementation of sensorless techniques for different operating speeds are described in this paper. Presented application has been implemented including the high frequency (hf) injection method and extended back EMF state observer on a single chip solution of DSC56F8300 series without any additional supportive circuitry. The extended back EMF algorithm with angular speed and position observer is suitable for sensorless control drive. It is also transferable for other motor types, e.g. synchronous reluctance- or synchronous one with 'smooth' rotor. The presented sensorless control has been proved in electric washer drive with very good operating properties.

\section{Introduction}

An important factor for using sensorless control in the drive applications is to optimize the total cost performance ratio of the overall drive cost. The systems should be less noisy, more efficient, smaller and lighter, more advanced in function and accurate in control with a low cost. To achieve efficient control of AC machines, knowledge of rotor position is essential. Different types of mechanical position transducers can be used to measure rotor position directly, but since solution with such transducer introduces additional cost alternative means of obtaining rotor position is highly desirable.

Sensorless control of AC machines has become a frequently discussed topic at engineering conferences. Many researchers and scientists have published papers on this topic but there are only a few articles that discuss complex implementation of the algorithms into a single application covering all operating conditions. Classical solution with six step commutation control (brushless DC motor) has several drawbacks; such as low efficiency, higher audible noise and lower developed torque when compared to sinusoidal control of PMSM. To increase efficiency of the drive, sinusoidal control is needed [1]. Here, all three phases of the inverter are constantly conducting current making observation of back-EMF zero crossing impossible. Therefore more complex sensorless algorithms must be employed.

Sensorless algorithms for sinusoidal control of AC machines can be broadly divided into two major groups; 1 ) those that utilize magnetic saliency for tracking rotor position [2]-[12] and 2) those that estimate rotor position from calculated motor model [8], [13] The later, requires accurate knowledge of phase voltages and current for proper functionality. At low speeds, phase voltage reference and measured phase current are low, making it very difficult to separate from noise. Also distortion by inverter non-linearities and model parameter deviation becomes significant with decreasing speed. Therefore methods based on motor model are not suitable for low rotor speeds.

For start-up and low speeds, additional carrier signal superimposed to the main excitation is required. This carrier signal adds needed excitation to the motor at low and zero speed, and its back analysis can provide a viable means of obtaining information about rotor position. The carrier injection methods however, require a certain amount of saliency present in the motor [3]. In IPMSM this saliency results from inductance variation [1] as is explained later in the paper. On the other hand, at high speeds the amplitude of back EMF is big enough for motor model and angle tracking observer to work properly, therefore no additional signal is required. In fact, additional hf signal deteriorates tracking accuracy of the angle tracking observer. Therefore injection of hf signal is not desired for high speed operation. It is obvious that in order to achieve full speed range sensorless operation of IPMSM, both techniques have to be employed, each covering different operational speed ranges. This requires algorithm that will ensure seamless blending of the estimates throughout the entire speed range.

The proposed solution is based on field oriented control of IPMSM with implemented speed control loop. This includes inner current control loop with implemented decoupling of cross-coupled variables achieving good torque control performance. To maximize converter efficiency and minimize its rating, current loop is designed with maximum torque/ampere criteria [1].

\footnotetext{
* R. Filka ${ }^{1}$, P. Balazovic ${ }^{1}$, B. Dobrucky ${ }^{2}$

${ }^{1}$ Freescale Semiconductor, 1. Maje 1009, Roznov p. Radhostem, Czech Republic, Roman.Filka@freescale.com

${ }^{2}$ University of Zilina, Faculty of Electrical Engineering, Univerzitná 1, 01026 Žilina, Slovakia
} 


\section{IPMSM Characterization}

\section{A. Motor Description}

Mathematical model of IPM synchronous motor in synchronous reference frame is described as follows

$$
\left[\begin{array}{l}
u_{d} \\
u_{q}
\end{array}\right]=r_{s}\left[\begin{array}{c}
i_{d} \\
i_{q}
\end{array}\right]+\left[\begin{array}{cc}
L_{d} s & L_{q} \omega_{r} \\
-L_{d} \omega_{r} & L_{q} s
\end{array}\right]\left[\begin{array}{c}
i_{d} \\
i_{q}
\end{array}\right]+\psi_{P M} \omega_{r}\left[\begin{array}{l}
0 \\
1
\end{array}\right]
$$

where

$s \quad$ - differential operator;

$u_{d q}$ - stator voltages in synchronous reference frame;

$i_{d q}$ - stator currents in synchronous reference frame;

$L_{d q}$ - direct and quadrature inductances;

$\omega_{r}$ - rotor speed;

$\psi_{P M}$ - permanent magnet flux;

Torque developed by the IPM synchronous motors as described by (2), can be divided into two components. First component of the torque is created by contribution of the $\psi_{P M}$ field and is called synchronous torque. Second component, referred to as reluctance torque, arises due to rotor saliency, where the rotor tends to align with the minimum reluctance.

$$
T_{e}=\frac{3}{2} p\left(\psi_{P M} i_{q}+\left(L_{d}-L_{q}\right) i_{d}\right)
$$

where

$p \quad$ - number of pole pairs

IPM motors have the permanent magnets buried inside the rotor, which makes them salient pole machines with small effective air-gap. Reluctance in q-axis direction is smaller than that one in $\mathrm{d}$-axis, resulting in q-axis inductance bigger than d-axis; $L_{d}<L_{q}$. Therefore, in order to develop maximal torque according to (2), reluctance torque should be utilized, i.e. $i_{d}$ current has to be adjusted to negative values, weakening the resulting magnetic field. On the other hand, the armature reaction effects are dominant, due to small effective air-gap, resulting in saturation of q-axis inductance according to the level of applied load. This phenomenon is particularly important, because magnetic saliency decreases proportionally with saturated inductance and disappears completely at certain load level. Furthermore, under load the torque current in q-axis winding creates a term $\psi_{P M} i_{q}$ causing air-gap flux distribution to move towards direction of q-axis. Since the HF signal injection sensorless algorithm estimates the position of saliency rather than the position of rotor itself, this phenomenon has to be accounted for in the final application.

\section{B. High Frequency Impedance}

In order to verify presence of magnetic saliency at high frequencies ( $h f$ ), $h f$ impedance measurements were carried out [4]. In these measurements, the rotor is mechanically locked to prevent current signals distortion. $H F$ signal of $50 \mathrm{~V} / 500 \mathrm{~Hz}$ is injected in $d_{m}$ - axis of the measurement $d_{m}-q_{m}$ reference frame. This frame is shifted from the actual rotor $d-q$ frame by angle_offset. Offsetting the measurement frame will ensure correct alignment of the frames any time the measurement is repeated. Injection of $h f$ voltage $u_{h f}=$
$=U_{m} \sin \left(\omega_{h f} t\right)$ into $d_{m}$ - axis, will result in $i_{d m}$ current as described by (3).

$$
\begin{aligned}
& i_{d m}=I_{d m_{-} \max } \sin \left(\omega_{h f} t+\varphi\right) \\
& =I_{d m_{\_} \max } \cos (\varphi) \sin \left(\omega_{h f} t\right)+I_{d m_{\_} \max } \sin (\varphi) \cos \left(\omega_{h f} t\right)
\end{aligned}
$$

Multiplying by $\sin \left(\omega_{h f} t\right)$ and $\cos \left(\omega_{h f} t\right)$ respectively will result in spectral separation of low and high frequency components. This allows removing of $h f$ component by simple low pass filtering of both products, resulting in (5), (6).

$$
\begin{aligned}
& i_{d m \_a}=\operatorname{LPF}\left[i_{d m} * \sin \left(\omega_{h f} t\right)\right]=\frac{1}{2} I_{d m} \cos (\varphi) \\
& i_{d m \_b}=\operatorname{LPF}\left[i_{d m} * \cos \left(\omega_{h f} t\right)\right]=\frac{1}{2} I_{d m} \sin (\varphi)
\end{aligned}
$$

In order to extract amplitude $I_{d m}$ from (5), and (6), sine and cosine functions have to be eliminated. This can be easily done by squaring $i_{d m_{a} a}$ and $i_{d m_{b} b}$ components respectively and subsequent addition (7). Then the amplitude $I_{d m}$ is calculated as in (8).

$$
\begin{aligned}
& I_{d m}{ }^{2}=4 *\left(\left(i_{d m_{\_} a}\right)^{2}+\left(i_{d m \_b}\right)^{2}\right) \\
& Z_{d m}=\frac{U_{m}}{I_{d m}}
\end{aligned}
$$

The algorithm as described by eq. (3)-(7) is implemented on 16-bit Freescale Semiconductor digital signal controller (DSC). Output of the algorithm is the square value of $I_{d m}$. Calculation of square root value of $I_{d m}$ from is done externally together with subsequent calculation of $h f$ impedance (8).

Since angle_offset is varied $\pm 180 \mathrm{deg}$. electrical, at $90 \mathrm{deg}$. $i_{d m}$ will correspond to $i_{q m}$. Therefore, to suppress DC offset of the $i_{d m}$ current under load, $1 \mathrm{~s}^{\mathrm{t}}$ order high pass filter with cut-off frequency $10 \mathrm{~Hz}$ is used. Block diagram showing the $h f$ impedance measurement algorithm as implemented in DSC is depicted on Fig. 1.

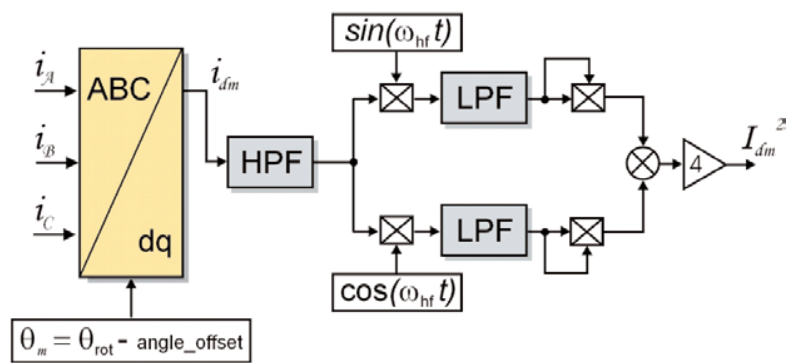

Fig. 1 Block diagram of HF impedance measurement

The obtained measurement results are shown on Fig. 2, where resulting impedance is plotted as a function of angle_offset and load level. It can be seen from Fig. 2 that the saliency moves towards the direction of q-axis and disappears with increasing load level as assumed in section II. A. Saliency disappearing with increasing load will cause eventual failure of sensorless algorithm based on 
saliency tracking. This can be avoided by proper compensation action in d-axis current [4], which however will introduce additional losses in the motor and decrease the efficiency of the control loop.

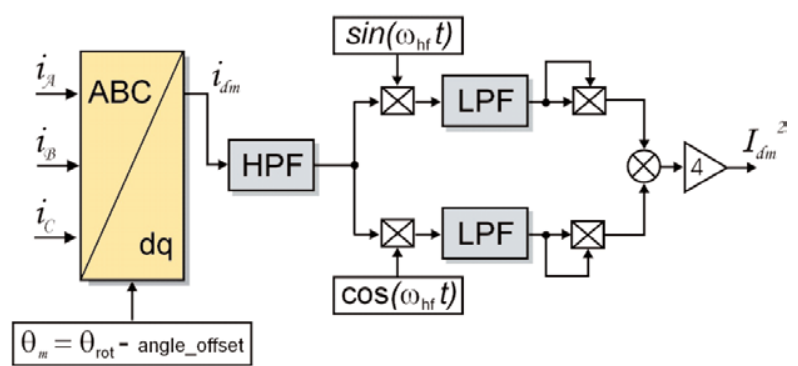

Fig. 2 High Frequency impedances as a function of difference between measurement and actual rotor reference frames and applied load.

\section{Design of sensorless control for IPMSM}

\section{A. Initial Position Detection}

As with any other synchronous motor, the first problem to overcome in FOC is the motor start-up. In contrast with the AC induction motor where the rotor flux is basically created from the stator, in the IPM motor the rotor flux is created by permanent magnets present in the rotor. In order to be able to use FOC, position of this rotor flux has to be known prior to any control action. In conventional IPM control with an encoder as a position transducer, an initial position is set by applying DC voltage in one motor phase, which creates a magnetic pole attracting the opposite pole of rotor magnets (alignment process). This process unavoidably generates often unwanted rotor movements. The sensorless algorithm based on injection of pulsating HF signal in the synchronous frame can be used to estimate the position of rotor at start-up. This sensorless approach is physically based on property of $d$ and $\mathrm{q}$ axes flux being decoupled [3]. Therefore, if an estimated $\hat{d}-\hat{q}$ reference frame is defined and not precisely aligned with a real rotor $d-q$ reference frame, then by applying flux vector at known carrier frequency, for example, in the $\hat{d}$ axis, current at carrier frequency can be observed in the $\hat{q}$ axis. This current is directly proportional to the misalignment angle of the estimated and rotor reference frame. Therefore, changing the position of the estimated frame such that this $\hat{q}$ axis current is zero or minimal, will allow for tracking the real rotor, i.e. saliency position.

Considering high frequency signals, the motor model from (1) can be rewritten into an estimated reference frame (9). In this hf IPMSM model, voltage drop across the stator resistance and back-EMF components can be neglected.

$$
\left[\begin{array}{c}
\hat{u}_{d} \\
\hat{u}_{q}
\end{array}\right]=\left[\begin{array}{cc}
Z_{1}+\Delta Z \cos \left(2 \theta_{\text {err }}\right) & -\Delta Z \sin \left(2 \theta_{\text {err }}\right) \\
-\Delta Z \sin \left(2 \theta_{\text {err }}\right) & Z_{1}-\Delta Z \cos \left(2 \theta_{\text {err }}\right)
\end{array}\right]\left[\begin{array}{c}
\hat{I}_{d} \\
\hat{I}_{q}
\end{array}\right]
$$

where

$$
Z_{1}=\frac{Z_{d}+Z_{q}}{2}, \frac{\Delta Z=Z_{d}-Z_{q}}{2}, \theta_{\text {err }}=\theta_{\text {rot }}-\theta_{\text {est }}
$$

$\hat{u}_{d q}$ - stator voltages in estimated frame;

$\hat{I}_{d q}$ - stator currents in estimated frame;

$\theta_{\text {rot }}$ - rotor position;

$\theta_{\text {est }}$ - estimated position;

$\theta_{\text {err }}$ - position error;

Applying high frequency signal $u_{h f}=U_{m} \sin \left(\omega_{h f} t\right)$ in d-axis of $h f$ model of (9), will result in high frequency currents

$$
\left[\begin{array}{c}
\hat{I}_{d} \\
\hat{I}_{q}
\end{array}\right]=-\frac{U_{m}}{\omega_{h f} Z_{d} Z_{q}} \cos \left(\omega_{h f} t\right)\left[\begin{array}{c}
Z_{1}-\Delta Z \cos \left(2 \theta_{\text {err }}\right) \\
-\Delta Z \sin \left(2 \theta_{\text {err }}\right)
\end{array}\right]
$$

After filtering and demodulation, $\hat{I}_{q}$ current is described as

$$
\hat{I}_{q}=-\frac{U_{m} \Delta Z}{2 \omega_{h f} Z_{d} Z_{q}} \sin \left(2 \theta_{e r r}\right)
$$

Fig. 3 depicts the $\hat{I}_{q}$ current in dependency on the rotor position $\theta_{\text {rot }}$. In this measurement the estimated position $\theta_{\text {est }}$ is kept zero in order to see variations in $\hat{I}_{q}$ current.

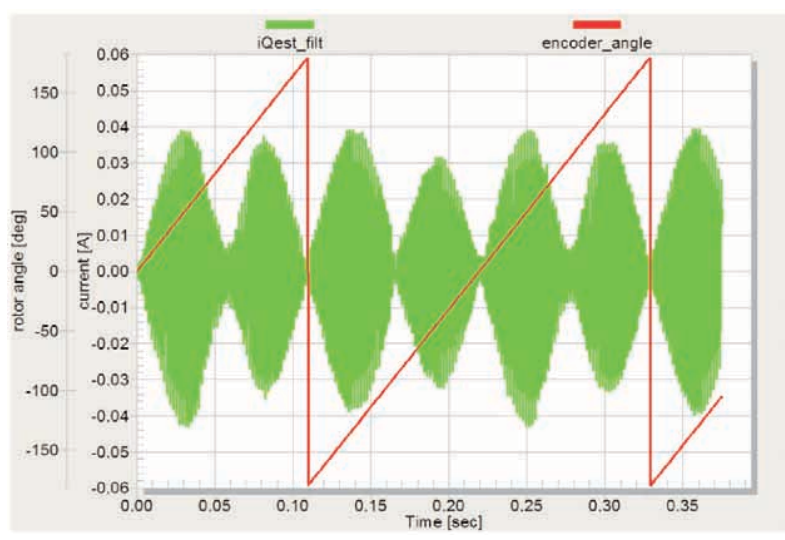

Fig. 3 Estimated quadrature axis current as a function of rotor position when estimated angle $=0$

The relationship between $\hat{I}_{q}$ and estimated position error from suggest to use a controller capable of driving its output such that $\hat{I}_{q}$ current will remain zero.

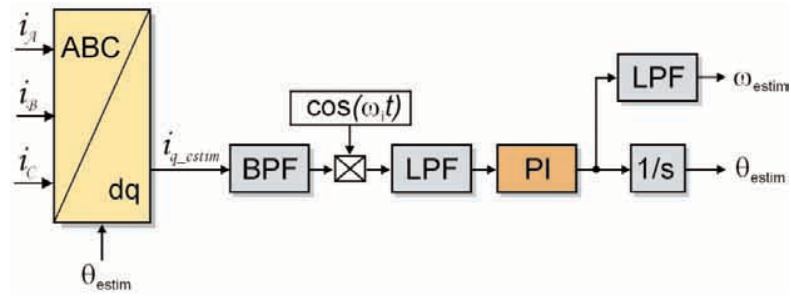

Fig. 4 Saliency tracking observer; as used for rotor position estimation at zero and low speeds 
The controller output represents the estimated speed, thus its integration yields position of the estimated reference frame. Such structure acts as a phase locked loop and its schematic block diagram is depicted in Fig. 4. Fig. 5 demonstrates experimental results of the initial Saliency Tracking Observer (STO) alignment, which is used for the start-up rotor position detection. The experiment is carried out with the rotor manually rotated to an arbitrary position and then running STO alignment process.

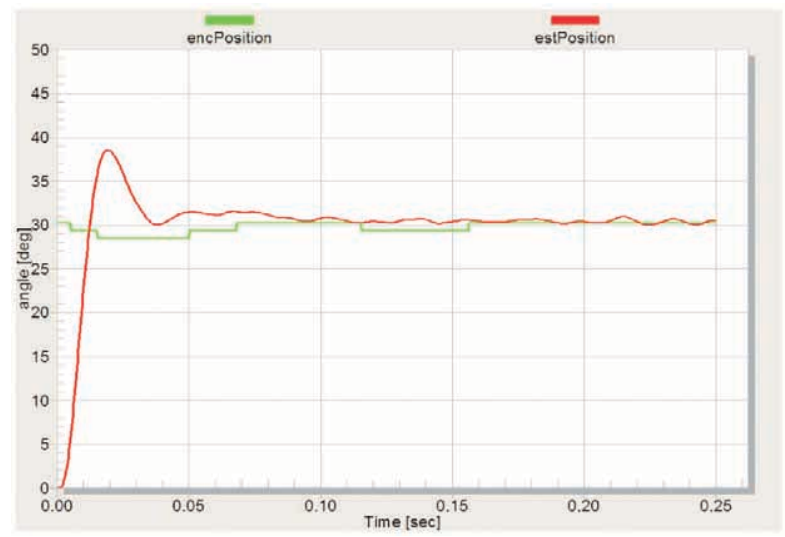

Fig. 5 Saliency tracking observer; initial position alignment

\section{B. Low Speed Sensorless Control}

The saliency tracking observer, as shown in Fig. 4, is used for start-up as well as for low speed sensorless control. A standard PI type controller is used, assuring zero position error in steady state. The saliency tracking loop is a non-linear structure but linearization around operation point $\theta_{\text {esto.p. }}=\theta$ rot allows approximation of the loop by

$$
\theta_{\text {est }} \theta_{\text {rot }}=\frac{K_{p} s+K_{I}}{s^{2}+K_{p} s+K_{I}}
$$

A standard PI type controller is considered in equation (13). Since the filtering and demodulation is done in the synchronous reference frame, the band pass filter (BPF) from Fig. 4, does not distort the phase of the estimated signal. Phase distortion is introduced by the low pass filter (LPF). Therefore, LPF affects the dynamics of the tracking loop and has to be accounted for in the loop tuning. Tuning of the saliency tracking loop is performed using $h f$ IPMSM model from , as shown on Fig. 6.

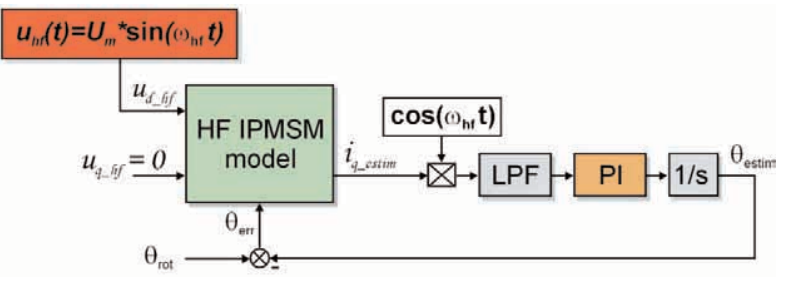

Fig. 6 Block diagram for tuning saliency tracking observer
It has to be noted however, that the carrier frequency limits STO bandwidth. Therefore, the PI controller should be designed so that STO will exhibit sufficient rejection capabilities at the carrier frequency.

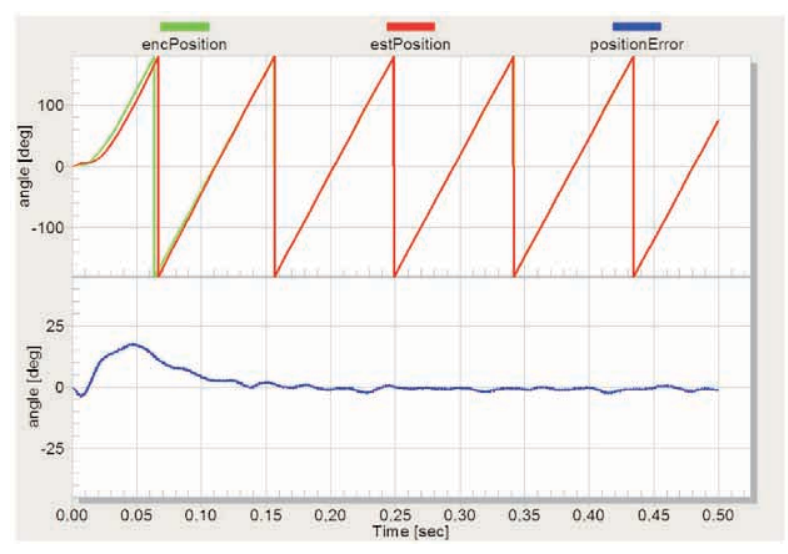

Fig. 7 Saliency tracking observer behaviour in open loop control during voltage transient $(0-\sim 45$ [rpm] $)$

Fig. 7 shows the behaviour of STO in the open loop low speed tracking mode, during input voltage transient. Here the q-axis voltage command is changed in step $0-10 \%$ of DC bus voltage, resulting in a sharp change in the rotor speed. Transient change generates the transient error in estimated position of $\sim 18$ deg electrical. Steady state estimation error of $3 \mathrm{deg}$. electrical has been achieved. The rotor speed settled at $\sim 45 \mathrm{rpm}$.

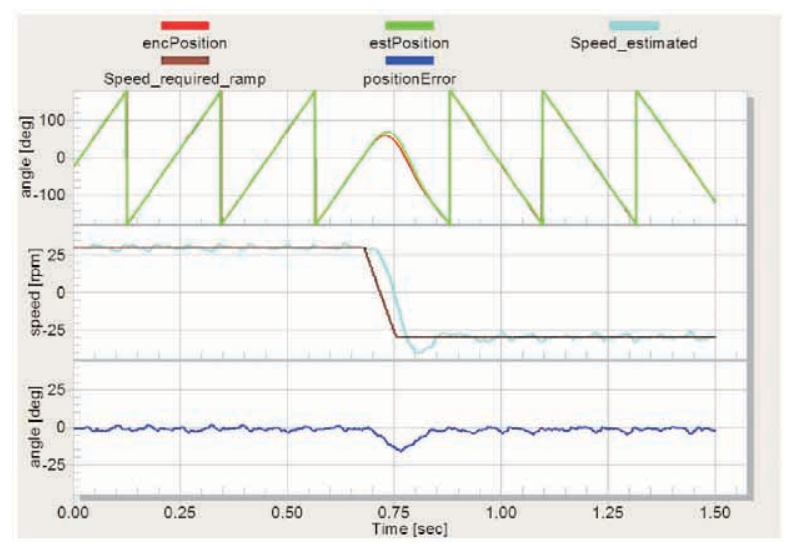

Fig. 8 Position error during reversal at 30rpm, IPMSM operated in full sensorless speed FOC

Position error during speed reversal at $30 \mathrm{rpm}$ is depicted on Fig. 8. Here the motor is operated in speed FOC with position and speed feedback provided by STO, i.e. full sensorless mode. The rotor position from encoder is used only for comparison with the estimated position. 
Experimental results of low speed full sensorless control with speed reversal under different load conditions are shown on Figs. 9 and 10. Rotor position information from encoder is not used in these experiments.

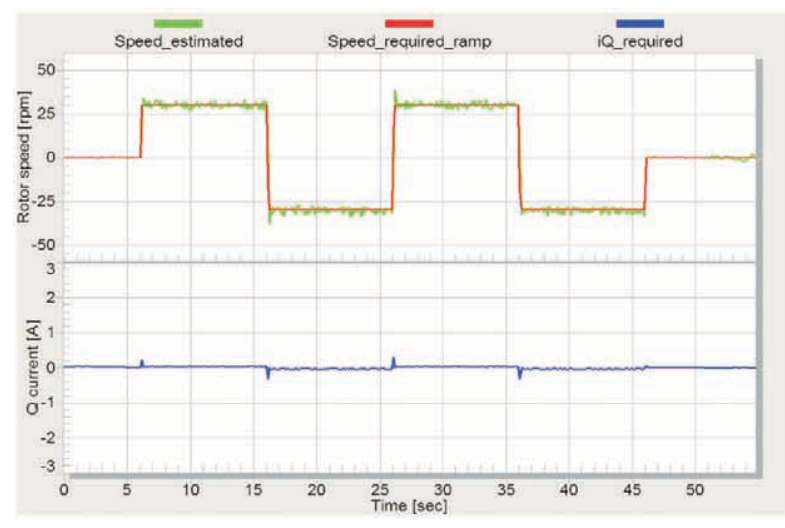

Fig. 9 Low speed full sensorless FOC, with speed reversal $\pm 30 \mathrm{rpm}$ under no load

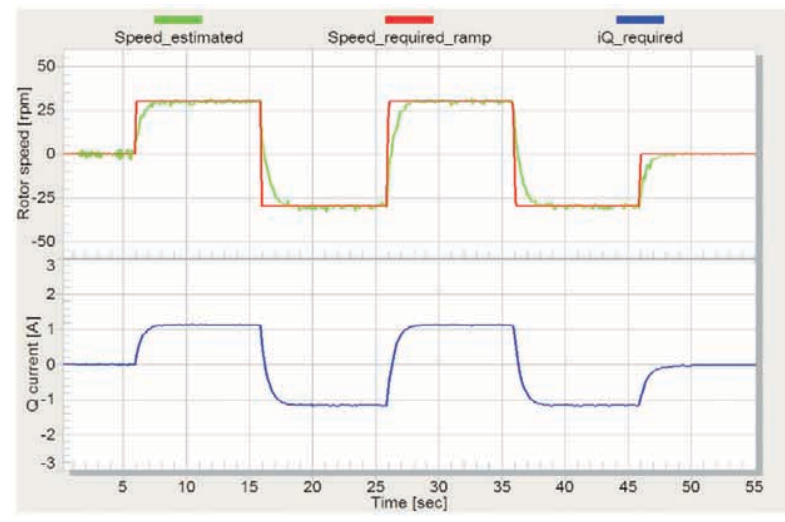

Fig. 10 Low speed full sensorless FOC, with speed reversal $\pm 30 \mathrm{rpm}$ under load (20\% nominal)

\section{High Speed Sensorless Control}

There have been proposed many sensorless control methods for surface permanent-magnet synchronous motors based on estimation of electromotive force in which the electrical position information of machine is encoded.
Fundamentally, these estimation methods for the position and velocity are based on the motor mathematical model. However, mentioned methods cannot be directly applied to an interior permanent-magnet synchronous motor, because the position information is contained not only in the conventionally defined back electro-motive force (EMF) but also in the definition of stator inductance as shown in (14).

Now the stator voltage $u_{s}$ is interpreted as a sum of four voltage vectors $u_{R}$ (voltage drop), $u_{L}$ (inductance drop) and conventional $u_{E}$ (back EMF), and $u_{R E L}$ (reluctance EMF). The last term of equation known as generated reluctance voltage is caused by motor saliency.

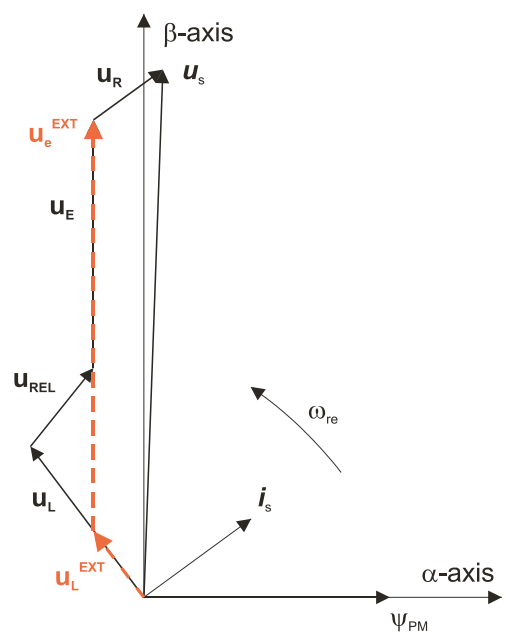

Fig. 11 Vector diagram of salient-pole machine.

The vector representation of given equation is displayed in Fig. 11. Unfortunately, the computation of position dependent information which is contained in two unknown voltage vectors conventional $u_{E}$, and $u_{R E L}$ makes difficulties to assess it. However, there has been proposed [] a simple way to resolve this problem by eliminating the $2 \theta \mathrm{e}$ term in (14) using a purely mathematical method.

Here is described a mathematical model of the interior PMSM motor which is based on an extended electro-motive force function [13]. This extended electro-motive force (EEMF) model includes both position information from the conventionally defined EMF and the stator inductance as well. Then, it makes possible to obtain

$$
\begin{aligned}
& \underbrace{\left[\begin{array}{l}
u_{\alpha} \\
u_{\beta}
\end{array}\right]}_{u_{s}}=\underbrace{R_{s} \cdot\left[\begin{array}{l}
i_{\alpha} \\
i_{\beta}
\end{array}\right]}_{\overline{u_{R}}}+\underbrace{p L_{0} \cdot\left[\begin{array}{l}
i_{\alpha} \\
i_{\beta}
\end{array}\right]}_{\overline{u_{L}}}+\underbrace{k_{e} \cdot \omega_{e} \cdot\left[\begin{array}{r}
-\sin \left(\theta_{e}\right) \\
\cos \left(\theta_{e}\right)
\end{array}\right]}_{\overline{u_{E}}}+\underbrace{2 \cdot \omega_{e} \cdot \Delta L \cdot\left[\begin{array}{cc}
-\sin \left(2 \theta_{e}\right) & \cos \left(2 \theta_{e}\right) \\
\cos \left(2 \theta_{e}\right) & \sin \left(2 \theta_{e}\right)
\end{array}\right] \cdot\left[\begin{array}{l}
i_{\alpha} \\
i_{\beta}
\end{array}\right]}_{\overline{u_{R E L}}}
\end{aligned}
$$

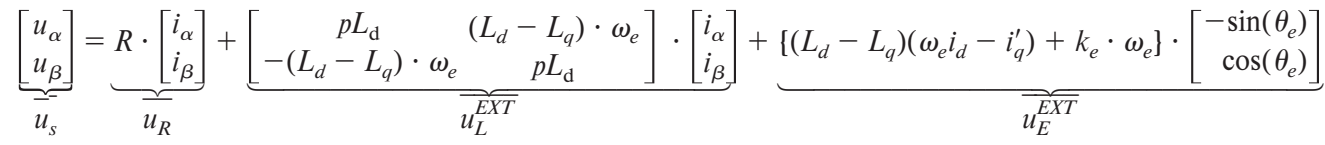


the rotor position and velocity information by estimating the extended EMF only.

In this equation (15) there is no $2 \theta_{e}$ dependent term comparing to the conventionally defined IPMSM machine model (14). The second term $u_{L}^{E X T}$ and third term $u_{E}^{E X T}$ on the right side of equation (15) are depicted in Fig. 11 as vectors in dashed yellow lines. The $u_{L}^{E X T}$ vector term in equation (15) can be explained as extension of conventional inductance voltage drop, and second vector term $u_{E}^{E X T}$ is considered as an extension of conventional back EMF term. It is obvious that extended inductance voltage drop $u_{L}^{E X T}$ has no position dependent information and only extended back EMF term $u_{E}^{E X T}$ possesses position depen ent information. This rewritten mathematical model of interior PMSM motor makes possible to express the extended back EMF term $u_{E}^{E X T}$ to be simply estimated using standard estimation approach of the surfacemounted PMSM motor.

$$
\left[\begin{array}{l}
u_{e \alpha} \\
u_{e \beta}
\end{array}\right]=\left\{\left(L_{d}-L_{q}\right)\left(\omega_{e} i_{d}-i_{q}^{\prime}\right)+k_{e} \cdot \omega_{e}\right\} \cdot\left[\begin{array}{r}
-\sin \left(\theta_{e}\right) \\
\cos \left(\theta_{e}\right)
\end{array}\right]
$$

In this term (16), besides the conventionally defined EMF generated by the permanent magnet, there is a kind of voltage related to the saliency of the interior PMSM motor. It includes the position information from both the EMF and the stator inductance. It is a general form of mathematical model for all the synchronous motors [13].

\section{State Observer of Extended Back EMF}

In this section the described state observer is applied to the interior PMSM motor with an estimator model excluding the extended EMF term. Then the extended EMF term can be estimated using the state observer as depicted in Fig. 12, which utilizes a simple observer of IPM motor stator current. Here presented state observer is realized within stationary reference frame $(\alpha \beta)$. The estimator of $\alpha$-axis consists of the stator current observer based on $R L$ motor circuit with estimated motor parameters. This current observer is fed by the sum of the actual applied motor voltage $\left(u_{\alpha}\right)$, cross-coupled rotational term which corresponds to the motor saliency $\Delta L$ and compensator $F_{c_{-}}(s)$ corrective output. Since the extended term of back EMF is not included in the interior PMSM motor observer model, the compensator $F_{c}(s)$ corrective output shown in Fig. 12 supplies the not modeled extended back EMF [14], [15]. The estimate of extended EMF term in $\alpha$-axis can be derived as follows

$$
\hat{E}_{\alpha}(s)=F_{c}(s) \cdot\left[I_{\alpha}(s)-\hat{I}_{\alpha}(s)\right]
$$

It is obvious that the accuracy of the back EMF estimates is determined by the correctness of used motor parameters $(\mathrm{R}, \mathrm{L})$ by fidelity of the reference stator voltage and by quality of compensator such as bandwidth, phase lag and so on. It is obvious from the extended EMF transfer function that even if the motor parameters are precisely matched, the estimates are limited by the compensator quality. This implies that the state observer bandwidth and its corresponding phase lag constraints the performance of used method. The same consequences apply for estimate of the extended EMF in $\beta$-axis.
If assumed a perfect match between motor parameters and its estimated counterparts, then the transfer function is given as

$$
\hat{E}_{\alpha}(s)=-E_{\alpha}(s) \cdot\left[\frac{F_{c}(s)}{s \hat{L}_{d}+\hat{R}_{s}+F_{c}(s)}\right]
$$

and this yields the parameter insensitivity within the bandwidth. This clearly implies that the state observer bandwidth determines the performance of this method. The angle tracking observer [16] shown in Fig. 12 is widely used for the estimation of the rotor angle. By employing the tracking observer, noise on the position estimate can be filtered out without adding lag to the estimate within its bandwidth [14], [16]. Note that mathematical expression of the tracking observer error is well known as the formula of the difference of two angles

$$
\sin \left(\theta_{e}-\hat{\theta}_{e}\right)=\sin (\theta) \cos (\hat{\theta})-\cos (\theta) \sin (\hat{\theta})
$$

and this denotes an observer error. In the case of minimal deviations out of the estimated rotor angle compared to the actual rotor angle, the observer error may be expressed in the following form

$$
\theta_{e}-\hat{\theta}_{e}=\sin \left(\theta_{e}-\hat{\theta}_{e}\right)
$$

The primary benefit of the angle tracking observer utilization, in comparison with the trigonometric method, is its smoothing capability [17]. This filtering is achieved by the integrator and PI controller, which are connected in series and closed by a unit feedback loop

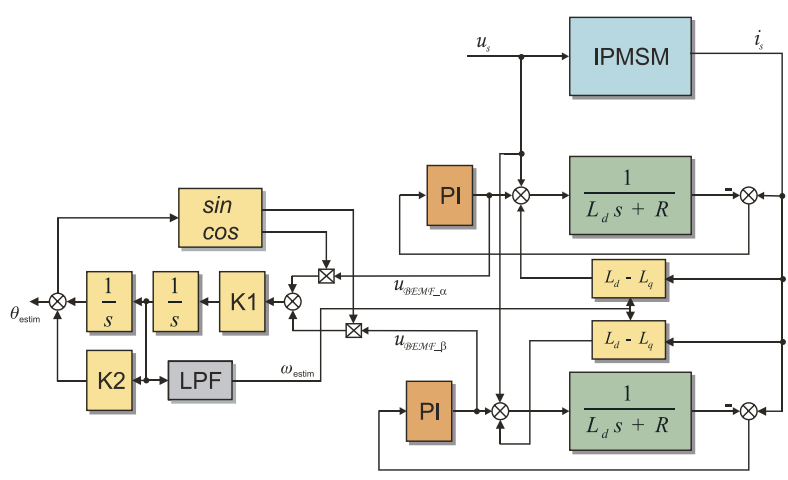

Fig. 12 Block diagram of state observer of extended back EMF

E. Experimetal Results of Extended Back EMF State Observer

The extended back EMF state observer was implemented using a digital signal controller of Freescale's 56F8300 series with interior PMSM. The motor with parameters summarized in Table IV was used for these experiments.

First, the experiments in tracking mode are presented, where field oriented control with operation of speed closed loop is used and the encoder transducer is used as position and speed feedback. 


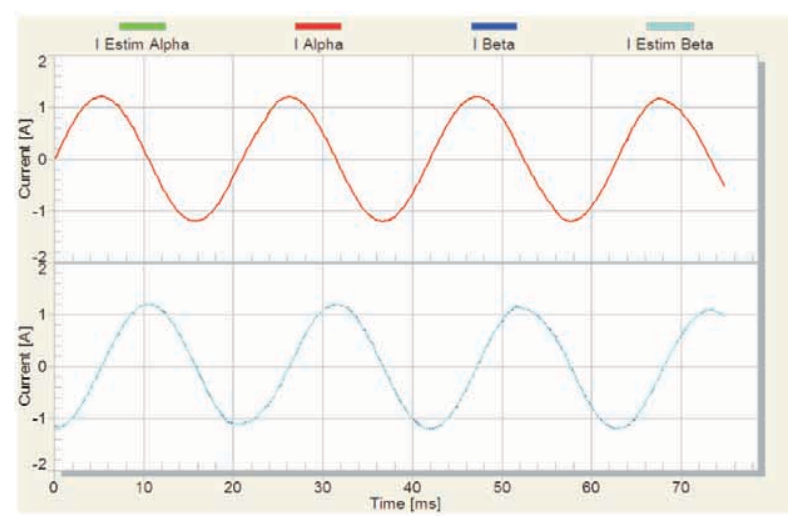

Fig. 13 Estimated $\alpha \beta$ currents by state observer at 300 [rad.sec ${ }^{-1}$ ]

Electrical rotor position and speed are fed back from the encoder transducer, and are granted as reference to estimated values of the rotor electrical position $\theta_{\text {estim }}$ and angular speed $\omega_{\text {estim }}$. This motor drive operation allows to evaluate the quality of sensorless algorithm. The observer tracking capability of phase stator currents expressed in a stationary reference frame are evaluated as shown in Fig. 13. It is apparent that there is very good signal fidelity between actual measured current of motor and estimated current value calculated by back EMF observer.

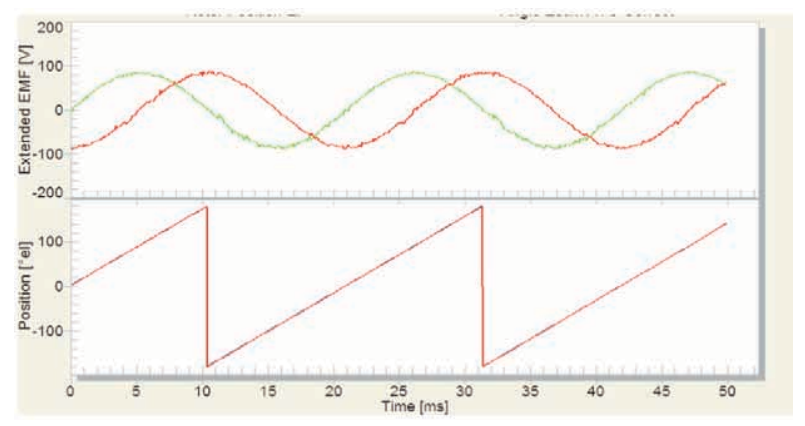

Fig. 14 Estimated extended EMF by state observer at $300\left[\mathrm{rad} . \mathrm{sec}^{-1}\right]$ and estimated electrical position by angle tracking observer

The interior PMSM motor under test operated in a tracking mode where speed control attained position and speed the from encoder, and estimation algorithm tracks the actual rotor position. As can be seen from Fig. 14, the estimation of speed and position have very good accuracy and apparently the encoder position feedback can be replaced by these estimates from the extended back EMF state filter.

The controller output, which corrects motor phase currents, is supplying not modelled part of motor state the extended back EMF. Fig. 14 shows the estimated extended back EMF at 300 $\left[\right.$ rad. $\mathrm{sec}^{-1}$ ].

If the interior PMSM motor drive operates in a sensorless mode where the electrical position required for vector transforma- tion is attained from sensorless algorithm and the feedback speed control loop is formed by state observer estimate. A satisfactory sensorless operation was achieved under different operation condition. As it can be seen from Fig. 14 there is a very high correspondence between the estimated rotor position (red) and encoder measurement of electrical position (blue). The exact knowledge of rotor position is very critical to the IPM motor stable operation and it is seen that in a sensorless mode the interior PMSM motor functions with minimum sensitivity to a motor load having very high agreement of the measured position from encoder and state filter estimate.

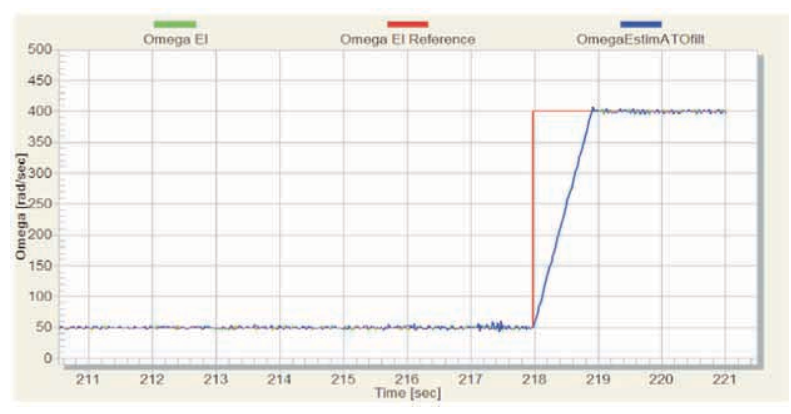

Fig. 15 Speed control with ramp acceleration under load condition

Since the state observer sensorless algorithm operates reliable from $50\left[\mathrm{rad} . \mathrm{sec}^{-1}\right]$, the speed command is demanded from this limit. A speed acceleration Fig. 15 from $50\left[\right.$ rad. $\mathrm{sec}^{-1}$ ] up to 400 $\left[\mathrm{rad} . \mathrm{sec}^{-1}\right]$ is tested with achieving almost identical behaviour of estimated and encoder speed.

The operation of sensorless IPM motor drive was tested under a variable load condition as shown in Fig. 16. The developed speed and position estimation algorithm demonstrates very good and stable speed estimation performance.

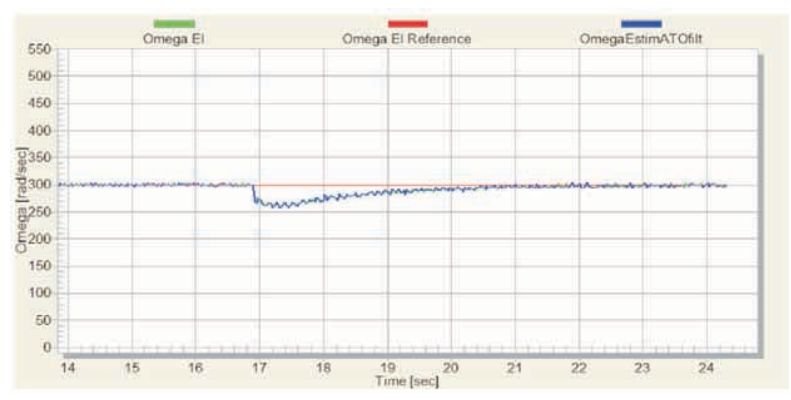

Fig. 16 Sensorless speed control at step change in load

A step change in the motor load was generated to verify dynamic performance of speed estimation and sensorless speed control, it can be seen in Fig. 15. Very stable drive operation during unexpected loading was observed. This makes this approach adequately robust to motor loading. 


\section{F. Whole Speed Sensorless Control}

In order to fully control IPMSM throughout the entire speed range, estimates from low and high speed sensorless algorithms have to be evaluated and merged. The proposed merging algorithm is based on cross-over functions, assuring smooth transition between algorithms. Moreover using cross-over functions allows completely switching off the algorithm currently not used [8], thus minimizing losses due to $h f$ injection at high speeds. Fig. 17 shows block diagram of algorithms for the whole speed sensorless control of IPMSM.

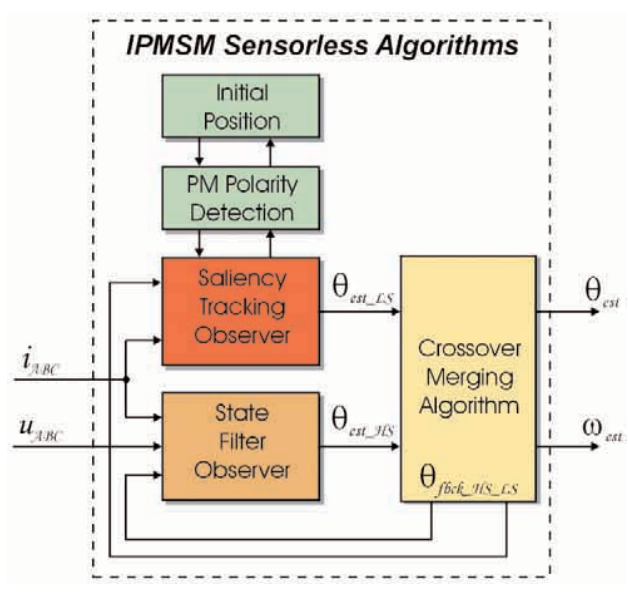

Fig. 17 Block diagram of IPMSM sensorless algorithms for entire speed range

Fig 18 shows experimental results of full IPMSM sensorless control obtained from experimental setup according to Fig. 19. In

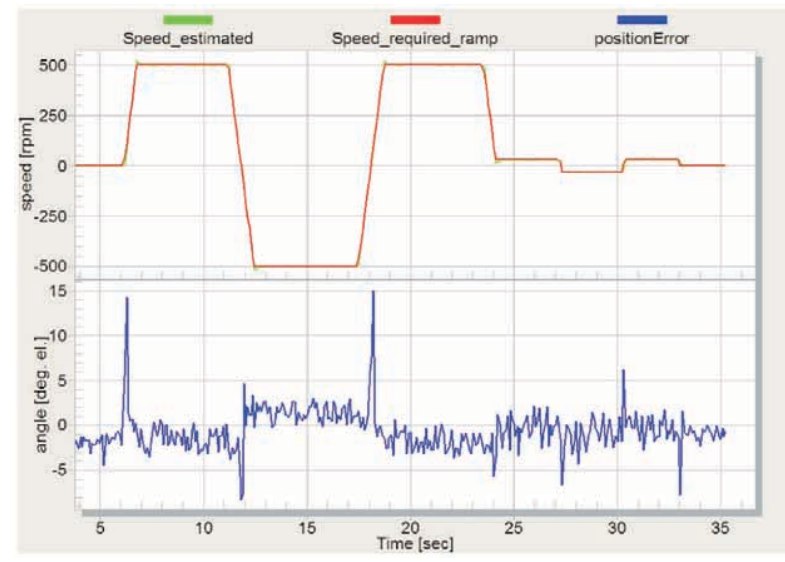

Fig. 18 Whole speed range full sensorless control with speed reversal this experiment IPMSM is operated in speed FOC with estimated position/speed provided by merging algorithm. Parameters of the IPMSM synchronous motor are given in Tab. I.

MOTOR PARAMETERS

TABLE I.

\begin{tabular}{|l|l|}
\hline Motor Parameter & Value \\
\hline Number of poles & 20 \\
\hline Rated speed & $600[\mathrm{rpm}]$ \\
\hline Phase voltage max. & AC $200[\mathrm{~V}]$ \\
\hline Phase current max & 8 A p-p \\
\hline Ke & $0.255[\mathrm{~V} \cdot \mathrm{sec} / \mathrm{rad}]$ \\
\hline Rs & $7.5[\Omega]$ \\
\hline Ld & $0.081[\mathrm{H}]$ \\
\hline Lq & $0.095[\mathrm{H}]$ \\
\hline
\end{tabular}

The overall structure of IPMSM sensorless drive for an electric washer is depicted on Fig. 19. IPMSM operated in speed sensorless FOC Position error is calculated with respect to the position obtained from the encoder. The encoder is used only for comparisons.

\section{Conclusion}

Sensorless field oriented control of IPMSM covering the entire speed range is presented. The merging algorithm based on a crossover function was designed in order to perform a smooth transition between two different sensorless algorithms. The approach presented in this paper is based on hf signal injection method for low speed operation and on the estimation of an extended EMF in the stationary reference frame using a state filter for high speed operation. The spatial information obtained from the estimates of extended EMF is used in an angle tracking observer to estimate the rotor electrical position. The extended EMF model includes both position information from the conventionally defined EMF and the stator inductance. This makes it possible to obtain the rotor position and velocity information by estimating the extended EMF only. Whole implementation of the transient injection method and extended back EMF state filter was achieved on a single chip solution of DSC56F8300 series without any additional supportive circuitry.

\section{Acknowledgement}

The authors wish to thank for the financial support to the Scientific Grant Agency of the Slovak Republic for project No. 1/3086/06 "Research of the new methods of modeling, control and simulation of mechatronic systems".

\section{References}

[1] BOSE, B.: Modern Power Electronics and AC Drives, Prentice Hall PTR, 2002.

[2] VADSTRUP, P., LORENZ, R. D.: Robust Estimator Design for Signal Injection-Based IPM Synchronous Machine Drives, Trans. of IEEE-IAS, 2004, pp. 957-963. 


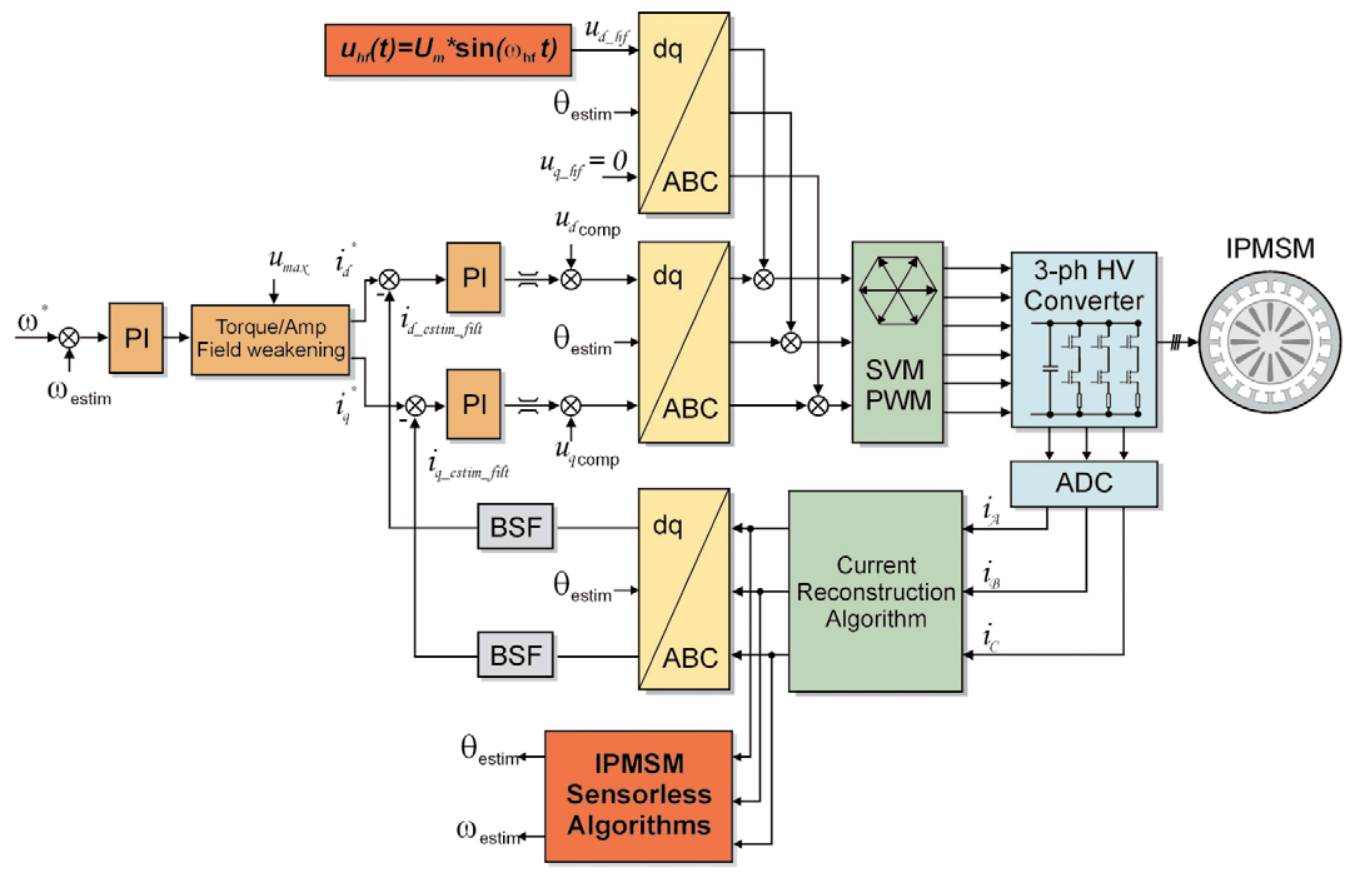

Fig. 19 Overall structure of IPMSM sensorless drive for electric washer

[3] HA, J., SUL, S. K., IDE, K., MUROKITA, I., SAWAMURA, K.: Physical Understanding of High Frequency Injection Method to Sensorless Drives of an IM, Trans. of IEEE, 2000, pp. 1802-1808.

[4] HA, J., IDE, K., SAWA, T., SUL, S. K.: Sensorless Position Control and Initial Position Estimation of an Interior Permanent Magnet Motor, Trans. of IEEE-IAS, 2001, pp. 2607-2613.

[5] JEONG, Y., LORENZ, R. D., JAHNS, T. M., SUL, S. K.: Initial Rotor Position Estimation of an Interior Permanent-Magnet Synchronous Machine Using Carrier-Frequency Injection Methods, IEEE Trans. on IA, vol. 41, 1/2005, pp. 38-45.

[6] KIM, H., HUH, K. K., LORENZ, R. D., JAHNS, T. M.: A Novel Method for Initial Rotor Position Estimation for IPM Synchronous Machine Drives, Proc. of IEEE, 2003, pp. 1173-1180.

[7] OGASAWARA, S., AKAGI, H.: An Approach to Real-Time Position Estimation at Zero and Low Speed for a PM Motor Based on Saliency, IEEE Trans. on IA, 1/1998, pp. 163-168.

[8] KIM, H., YI, S., KIM, N., LORENZ, R. D.: Using Low Resolution Sensors in Bumpless Estimation Methods for Low Cost PMSM Drives, Trans. of IEEE-IAS, 2005, pp. 2518-2525.

[9] KIM, J. M., SUL, S. K.: Speed Control of Interior Permanent Magnet Synchronous Motor Drive for the Flux Weakening Operation, Trans. of IEEE, 1/1997, pp. 43-48.

[10] IDE K., HA, J., M. SAWAMURA, IURA, H. AND YAMAMOTO, Y.: HF Injection Method Improved by Flux Observer for Sensorless Control of an IM, in Proc. of PCC-Osaka, 2002, pp. 516-521.

[11] DOBRUCKÝ, B., BALAŽOVIČ, P., FILKA, R., ABDALMULA M.A.R.: Robotic Servo-System with Sensorless Measurement of Initial Position of PMSM Motor Using PC\&ADSP21062 Control, in Proc. of RAAD’01 Conf., Vienna (AT), May 2001

[12] ABDALMULA, M.A.R., DOBRUCKÝ, B., PAVELKA, P.: Combined Method for Position Determination of PMSM in Zero- and Low Range of the Speed, Proc. of EDPE'03 Conference, Sep. 2003

[13] CHEN, Z, TOMITA, M., DOKI, S., OKUMA, S.: An extended electromotive force model for sensorless control of interior permanentmagnet synchronous motors, IEEE Trans. on Industrial Electronics, 4/2003, pp. 288-295.

[14] DOČAR, M., BUDAY, J.: Control System and Drives of OJ-10 Robotic operation Unit (in Slovak), Výkonová elektronika, zborník ZTSEVÚ, N. Dubnica, 3/1983, pp. 3-9.

[15] LORENZ, R. D.: Observers and state filters in drives and power electronics, Conf. Rec. of the IEEE IAS OPTIM, May 2002.

[16] MIENKINA, M., PEKAREK, P., DOBES, F.: 56F80x resolver driver and hardware interface, Application Note AN1942, Freescale Semiconductor Inc., 2005.

[17] FILKA, R., BALAZOVIC, P.: Intelligent sensorless control of AC permanent magnet motors, Embedded Control Europe, October 2005, pp. 17-19.

[18] FRANKLIN, G. F., POWELL, J. D., EMAMI-NAEINI, A.: Feedback Control of Dynamical System, 4th edition, Prentice-Hall, 2002. 